\title{
Reduced hemispheric asymmetry of the auditory N260m in dyslexia
}

\author{
Isabella Paul*, Christof Bott, Sabine Heim, Carsten Eulitz, Thomas Elbert \\ University of Konstanz, Department of Psychology, PO-Box D 25, 78457 Konstanz, Germany
}

\begin{abstract}
Dyslexia seems to be related to a lack of planum temporale (PT) asymmetry that is accompanied by functional differences to control subjects in both left and right hemispheric temporal regions during language tasks. PT asymmetry has been found to correlate with phonological and verbal skills. In accordance, reduced asymmetry of the auditory N100m sources in dyslexic adults and P100m sources in dyslexic children has been reported. These results might also be related to an atypical PT symmetry or the recruitment of other structures than the PT for speech processing in dyslexia. In the present study we tried to replicate and extend previous findings by examining a sample of 64 dyslexic and 22 control children in the MEG. We measured cortical activity during a passive auditory oddball-paradigm and localised ERF sources evoked by the standard stimulus $/ \mathrm{ba}$. Reduced hemispheric asymmetry in the localisation of the auditory $\mathrm{N} 260 \mathrm{~m}$ was revealed. While control children displayed a typical asymmetrical pattern with more anterior sources in the right hemisphere, this asymmetry was not present for the dyslexic children. Further, a correlation between N260m asymmetry and spelling test performance was found. Our results suggest that localisation of ERF components is indeed an applicative tool for investigating cortical deviances in dyslexia. A lack of source localisation asymmetry in dyslexia appears to be a robust finding across different samples of dyslexic children and adults. It appears that cortical auditory (language) processing is organised differently in dyslexic subjects than in controls. This might be the consequence of a more symmetrical PT organisation, which in turn might be the result of maturational delay.
\end{abstract}

Keywords: Hemisphere; Auditory N260m; Dyslexia

\section{Introduction}

Dyslexia has been related to an atypical organisation of auditory cortical areas. Heim, Eulitz, and Elbert (2003a) measured event-related fields (ERFs) after auditory speech stimulation and found more posterior source localisations of the $\mathrm{N} 100 \mathrm{~m}$ in the right hemisphere for dyslexic adults and for the P100m in children (Heim, Eulitz, \& Elbert, 2003b) compared to control subjects.

Typically, right hemispheric sources of auditory processing are found to localise more anterior to sources in the left hemisphere in normally literate subjects (Eulitz, Diesch, Pantev, Hampson, \& Elbert, 1995; Ohtomo et al., 1998; Paetau, Ahonen, Salonen, \& Sams, 1995; Teale, Sheeder, Rojas, Walker, \& Reite, 1998). This has generally been

* Corresponding author. Tel:: +497531 88 3301; fax: +497531 884601 . E-mail address: lsabella.Paul @uni-konstanz.de (I. Paul). explained with morphology differences of the planum temporale (PT) between the two hemispheres. The PT is located in the supratemporal cortex, posterior to Heschl's gyrus within the Sylvian fissure. The left planum is larger than the right planum in adults (see Steinmetz, 1996; Toga \& Thompson, 2003 for reviews) and children (Galaburda \& Geschwind, 1981; Geschwind \& Galaburda, 1987). This asymmetry increases during adolescence (Sowell et al., 2002) and has therefore been linked to hemispheric differences in white matter maturation (Thompson et al., 2000).

Although questioned by some authors (Rumsey et al., 1997; Shapleske, Rossell, Woodruff, \& David, 1999), PT asymmetry was found to be reduced or even reversed in dyslexic populations (Galaburda, Sherman, Rosen, Aboitiz, \& Geschwind, 1985; Humphreys, Kaufmann, \& Galaburda, 1990; Hynd, Semrud-Clikeman, Lorys, Novey, \& Eliopulos, 1990; Larsen, Hoien, Lundberg, \& Odegaard, 1990; Schultz et al., 1994). Eckert, Lombardino and Leonard (2001) showed 
that PT asymmetry was correlated with phonological and verbal skills, i.e. children with more symmetrical PT performed lower in verbal tests. The authors note that mainly the size of the right PT predicted task performance: right PT size was negatively correlated with phonological skills. A lack of PT asymmetry has also been reported for children with specific language impairment (Gauger, Lombardino, \& Leonard, 1997; Jernigan, Hesselink, Sowell, \& Tallal, 1991), which is considered to widely overlap with dyslexia in phenotype and etiology (Bishop \& Snowling, 2004).

The planum temporale is part of Wernicke's area and is considered to be dedicated mainly to language processing (Fiez, Raichle, Balota, Tallal, \& Petersen, 1996). Yet, it has also shown to be active during stimulation with non-speech sounds (Engelien et al., 1995; Tzourio et al., 1997). Jäncke, Wüstenberg, Scheich and Heinze (2002) point out that the PT might not be solely sensitivity to speech but rather to any kind of sounds containing fast frequency changes. Several functional imaging studies using fMRI or PET have revealed activation differences between dyslexic and control subjects in the PT and adjacent areas. Brunswick, McCrory, Price, Frith and Frith (1999) reported reduced activity in the Wernicke's area for their dyslexic sample during loud and silent reading. Further, dyslexic subjects had a lower level of activation in temporo-parietal and other perisylvian areas during phonological tasks (Paulesu et al., 1996; Rumsey et al., 1997; Temple et al., 2001). Shaywitz et al. (1998) measured cortical activation during five tasks with increasing demand on phonological decoding. Control subjects showed an activity increase in Wernicke's area, angular gyrus and striate cortex corresponding to phonological demand. This activation increase was not found for the dyslexic subjects. Thus, while dyslexics and controls did not differ in activation during visual, non-phonological tasks, they did differ during phonological tasks.

Group differences in the studies described above were mainly found in left hemispheric regions. However, the right hemisphere has also been reported to be deviant in dyslexia. McCrory, Frith, Brunswick and Price (2000) found reduced activity in right superior temporal and post central regions for dyslexic subjects during repetition of words and pseudowords. The authors explain this right hemispheric underactivation as decreased processing of non-phonetic speech aspects thus allowing the allocation of more processing capacity towards left hemispheric phonological language aspects.

To summarise, dyslexia seems to be related to a lack of PT asymmetry that is accompanied by functional differences to control subjects in both left and right hemispheric temporal regions during language tasks.

There is little research on localisation of auditory ERFs or event-related potentials (ERPs) making use the more timingsensitive measures of MEG or EEG. To our knowledge, the experiments of Heim et al. (2003a,b) have been the only ones so far investigating differences in source localisation following speech stimuli between dyslexic and control subjects.
They found localisation differences between the groups for the $\mathrm{N} 100 \mathrm{~m}$ component in adults, and for the $\mathrm{P} 100 \mathrm{~m}$ component as well as the M210 response in children. These results have been interpreted as a reflection of atypical PT symmetry or the recruitment of other structures than the PT for speech processing.

In the present study we tried to replicate and extend these findings by using a larger sample of dyslexic $(n=64)$ and control children $(n=22)$ within a narrower age range (8-10 years). The latter aspect is of importance, since the morphology of ERPs and ERFs is subject to developmental changes throughout childhood (Albrecht, Suchodoletz, \& Uwer, 2000; Ceponiene, Rinne, \& Näätanen, 2002; Ponton, Eggermont, Khosla, Kwong, \& Don, 2002; Rojas, Walker, Sheeder, Teale, \& Reite, 1998; Takeshita et al., 2002). We measured cortical activity during an auditory oddball-paradigm in the MEG and localised ERF sources evoked by the standard stimulus / ba/. Our results suggest that localisation of ERF components is indeed an applicative tool for investigating cortical deviances in dyslexia.

\section{Methods}

\subsection{Generation of the sample and behavioural tests}

The participating children were contacted through 14 primary schools in or around Konstanz, Germany, and attended either 3rd or 4th grade. Schools were asked to name children with massive problems in reading and spelling, as well as children without any such difficulties. In order to objectively classify the children to be dyslexic, all children underwent a test-battery that was designed to assess a variety of abilities ranging from spelling and reading to phonological abilities (DRT [Diagnostischer Rechtschreibtest 3rd grade (Müller, 1997); 4th grade (Grund, Haug, \& Naumann, 1994)]: standardised spelling test; ZLT [Zürcher Lesetest (Grissemann, 2000)]: Standardised reading test; SPM [Standard Progressive Matrices, German version (Heller, Kratzmeier, \& Lengfelder, 1998)]: non-verbal IQ-test; non-standardised word reading: list of words with increasing difficulty to be read aloud; non-standardised pseudoword reading: list of pseudowords with increasing difficulty to be read aloud; Mottier test (Welte, 1981): pseudowords with increasing difficulty are read aloud by the experimenter and are to be repeated by the child; dictation (Findeisen \& Melenk, 1991): only words were used that are spelled as one "hears" them, i.e. no knowledge about spelling rules or exceptions is necessary; categorical perception: judgement, if a syllable sounds more than "ba" or "da", when the formant transition period of the syllable is varied on a 10 -item continuum ${ }^{1}$ ). If a child, who was

\footnotetext{
1 Item 1 on the 10 -item continum ( 12 items per step) represents a clear /bai, item 10 a clear $/ \mathrm{da} /$. Categorical perception performance is quantified by the following formula with ai representing the number of responses for $/ \mathrm{ba} /$ and bi the number of responses for $/ \mathrm{da}$. A high categorical per-
} 
Table 1

Demographic information

\begin{tabular}{lllll}
\hline Group & $N$ & Age in years & Right-handers (\%) & Male (\%) \\
\hline Dyslexic & 64 & $9: 5$ & 85 & 70 \\
Control & 22 & $9: 6$ & 96 & 64 \\
\hline
\end{tabular}

suggested to be dyslexic by the teacher, was not significantly worse than the norm-sample in the standardised spelling test, he/she was excluded from the study. Control children who performed significantly worse than the norm-sample in the spelling test were either excluded or classified as dyslexic.

\subsection{Subjects}

Altogether, 64 children with dyslexia and 22 children without any reading or spelling deficits participated in the study. Table 1 shows the number of subjects per group, handedness and gender distributions.

Table 2 depicts that test performance of the dyslexic children was below test performance of the control children in all measures. Note that for the dyslexic group, the average $T$-value was 51.4 (ranging from 41 to 80 ) in the non-verbal intelligence test SPM and 36.8 (ranging from 22 to 48 ) in the spelling test ( $T$-value were derived from comparisons with age-matched norm-samples). It was required that the DRT test performance was below average $(T=50)$ and the discrepancy between DRT and SPM performance was at least $10 T$-value ( 1 standard deviation). In German-speaking countries, the diagnosis of dyslexia is based on spelling performance rather than on reading performance. Thus, reading performance was not used as a primary diagnostic criterion. Nevertheless, Table 2 depicts, that reading performance was also significantly worse in the dyslexic group than in the control group.

\subsection{Stimulation in the $M E G$}

Two synthesized consonant-vowel (CV) syllables /ba/ and $/ \mathrm{da} /$ were used for auditory stimulation in an oddball task. Both syllables were $250 \mathrm{~ms}$ long with a $40 \mathrm{~ms}$ formant transition period in the beginning that encoded the consonant information and thereby distinguished the syllables. For both syllables the fundamental frequency of formant $\mathrm{F} 0$ was $128 \mathrm{~Hz}$ with a linear decline to $109 \mathrm{~Hz}$ towards the end of the stimulus. The formant frequencies for the vowel /a/ (which was also the same for both syllables) were 770,1340 and $2400 \mathrm{~Hz}$ for F1, F2 and F3, respectively. Starting frequencies for the formants $\mathrm{F} 2$ and $\mathrm{F} 3$ were 1365 and $2337 \mathrm{~Hz}$ for $/ \mathrm{ba} /$, 1567 and $2515 \mathrm{~Hz}$ for / da/. Therefore, the only acoustical difference between the syllables was between formants F2 and

ception index indicates reliable and correct categorisation of $/ \mathrm{ba} /$ and $/ \mathrm{da} /$ $f=\sqrt{\sum_{i=1}^{10}\left(a_{i}-b_{i}\right)^{2}}$.
F3 within the first $40 \mathrm{~ms}$. Syllable $/ \mathrm{ba} /$ was used as standard stimulus, /da/ was used as deviant. All in all 500 stimuli were presented binaurally via a tube system with a constant ISI of $500 \mathrm{~ms}$. Occurrence rates were 85 and $15 \%$ for $/ \mathrm{ba} /$ and $/ \mathrm{da} /$, respectively. Stimuli were presented pseudo-randomly. Deviant stimuli were not analysed, neither were data epochs with standard stimuli occurring directly after a deviant. Stimuli were presented $60 \mathrm{~dB} / \mathrm{SPL}$ above the individual hearing threshold.

\subsection{MEG recordings}

Recording was done with a 148-channel magnetometer (MAGNES $^{\text {TM }} 2500 \mathrm{WH}, 4 \mathrm{D}$ Neuroimaging, San Diego, USA). Subjects were lying supine in a comfortable position in the magnetically shielded room (Vakuumschmelze Hanau). Auditory stimuli were presented through ear tubes $60 \mathrm{~dB} / \mathrm{SPL}$ over the individual hearing level. For artefact control, eye movements (EOG) were recorded from four electrodes attached to the left and right outer canthus and above and below the right eye, as well as cardiac activity (ECG) via two electrodes, one on each forearm. A SynAmps amplifier (NEUROSCAN) served for the recording of EOG and ECG. A video camera installed inside the chamber allowed monitoring the subject's behaviour and compliance at any time throughout the experiment.

Subjects were instructed to not pay any attention to the syllables they would hear. To distract attention, a silent video was screened onto a white projection field at the ceiling of the chamber using a video beamer (JVC ${ }^{\mathrm{TM}}, \mathrm{DLA}-\mathrm{G} 11 \mathrm{E}$ ) and a mirror system. Data were recorded with an online high-pass filter of $0.1 \mathrm{~Hz}$ and a sampling rate of $508.63 \mathrm{~Hz}$ (bandwidth $100 \mathrm{~Hz}$ ). Recording was continuous.

\subsection{Data analysis}

Data were noise-teduced and corrected for cardiac activity. For each subject data epochs with a $200 \mathrm{~ms}$ baseline and a post-trigger window of $800 \mathrm{~ms}$ were analysed. Epochs containing artefacts (signals $>120 \mu \mathrm{V}$ in the EOG and signals $>5 \mathrm{pT}$ in the MEG-channels) were rejected. The remaining epochs were averaged. The resulting average files were $20 \mathrm{~Hz}$ low-pass-filtered and baseline-corrected. Single equivalent dipoles (ECDs) were fitted for the average files, one per sampling-point in each hemisphere (using software provided by $4 \mathrm{D}$ Neuroimaging, San Diego, USA). ECDs were free in location and orientation (moving dipoles). The following channel groups were used for analysis (Fig. 1):

Standard left and right channel groups were chosen, since they are considered to cover most temporal activity.

The following ECD-parameters were analysed at the RMS peak latency in two different time-windows (Component 1: 50-160 ms, Component 2: $170-350 \mathrm{~ms}$ ): (1) three-dimensional ECD location ( $x$-axis position: posterior-anterior; $y$-axis position: medial-lateral, $z$-axis position: inferior-superior); (2) dipole strength; (3) RMS 
Table 2

One way ANOVAs of dependent variables SPM, DRT ( $T$-value); ZLT correctness, word reading correctness, pseudoword reading correctness, Mottier test, dictation (\% correct); word reading time, pseudoword reading time (s); ZLT reading time (s/no words); categorical perception (index), and GROUP (control, dyslexic) as between group factor

\begin{tabular}{|c|c|c|c|c|}
\hline & Control & Dyslexic & $F(1,84)$ & $p$ \\
\hline $\operatorname{SPM}(T)$ & 62.2 & 51.4 & 14.65 & $<0.0002$ \\
\hline $\operatorname{DRT}(T)$ & 57.8 & 36.8 & 213.14 & $<0.0001$ \\
\hline ZLT correctness (\% correct) & 96 & 87 & 23.58 & $<0.0001$ \\
\hline ZLT reading time (s/no words) & 0.67 & 1.41 & 24.58 & $<0.0001$ \\
\hline Word reading corectness ( $\%$ correct) & 90 & 74 & 33.6 & $<0.0001$ \\
\hline Word reading time $(s)$ & 72.5 & 166.7 & 33.4 & $<0.0001$ \\
\hline Pseudoword reading correctness (\% correct) & 75 & 52 & 38.79 & $<0.0001$ \\
\hline Pseudoword reading time (s) & 115.4 & 216.3 & 15.13 & $<0.0002$ \\
\hline Mottier test (\% correct) & 83 & 66 & 22.51 & $<0.0001$ \\
\hline Dictation (\% conect) & 93 & 75 & 40.5 & $<0.0001$ \\
\hline Categorical perception index $(F(1,68))^{a}$ & 31 & 25 & 18.42 & $<0.0001$ \\
\hline
\end{tabular}

a Data were available for 21 control children and 54 dyslexic children.

peak latency. ECDs, that did not match the following criteria, were excluded from further analysis: (1) $x$-axis position: $-1 \mathrm{~cm}<X<4 \mathrm{~cm}$; (2) $y$-axis position: $X>2 \mathrm{~cm}$; (3) goodness of fit $>0.9$. Statistical analysis was done with mixed models using the PROC MIXED module of SAS ${ }^{T M}$. The ECD-parameters described above were analysed per person, and per component. GROUP (control, dyslexic) and HEMTPSHERE (left, right) were fixed effects; PAT (subject) nested within GROUP was used as random factor. The variance structure used was variance components (VC). Least square means were estimated with the restricted maximum likelihood method (REML), plots show standard errors. Post hoc testing was done using the test of Tukey-Kramer. Effect sizes were calculated (Cohen's $d$ and $r$ ). For investigation of possible relationships between ECD localisation and behavioural performance, an asymmetry index was calculated ( $x$-axis position (right) $-x$-axis position (left)) for subjects, where ECD fits met inclusion criteria for both hemispheres ( 20 controls, 49 dyslexics). Correlations were calculated between the asymmetry index and test performance. Finally, the dyslexic children were sub-divided into two groups based on their phonological abilities (see Section 3). ECD-parameters were statistically analysed as described above with the difference that the GROUP factor was good (good phonological abilities) and poor (poor phonological abilities).

\section{Results}

Fig. 2 shows the grand mean signal of all MEG channels for the control children. An early component around $100 \mathrm{~ms}$ and a later component around $260 \mathrm{~ms}$ are clearly identifiable.

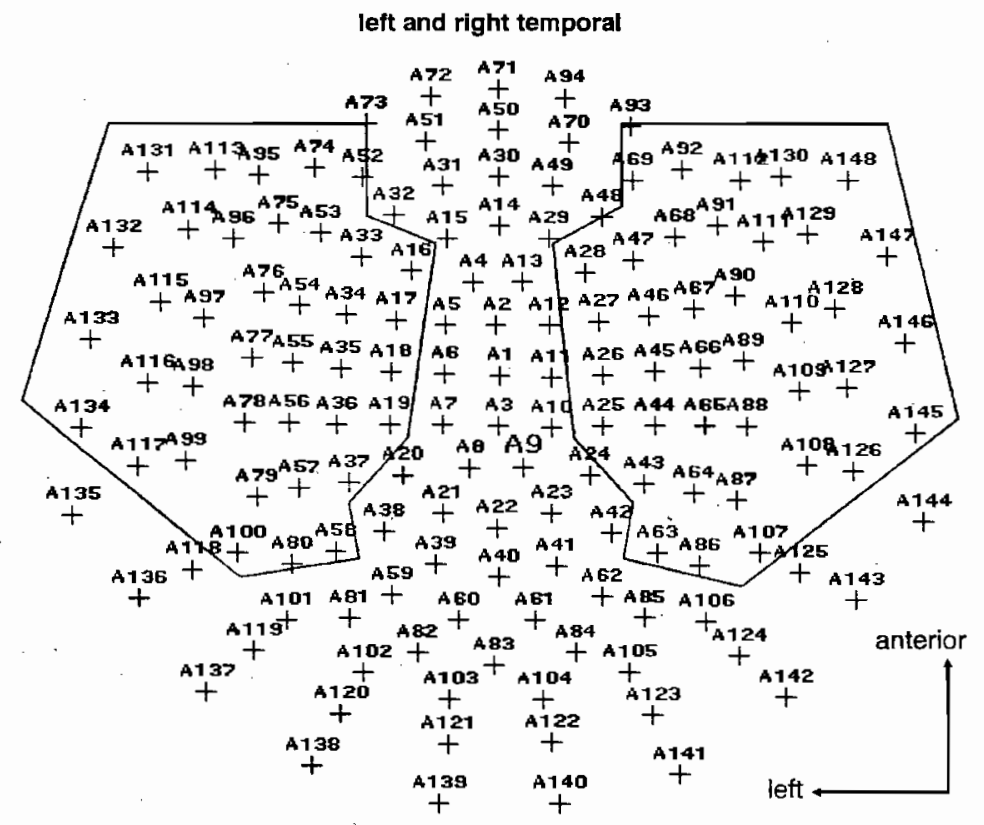

Fig. 1. Channel groups. 

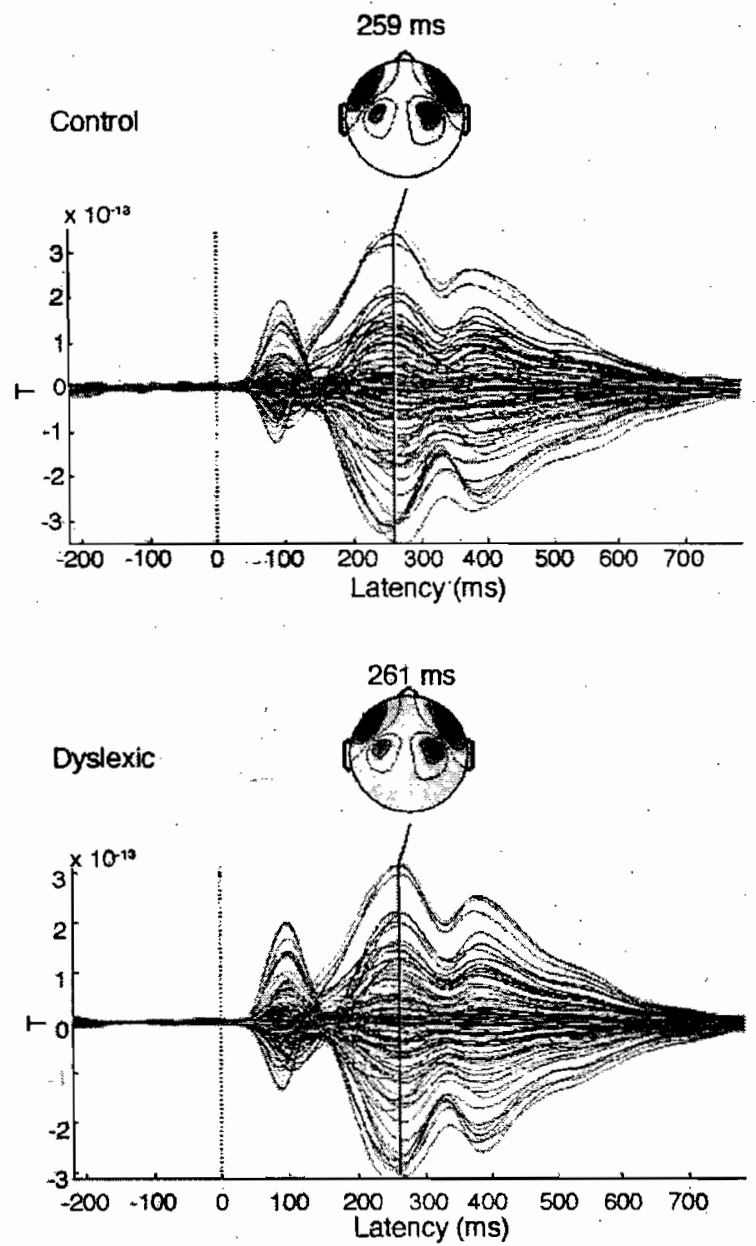
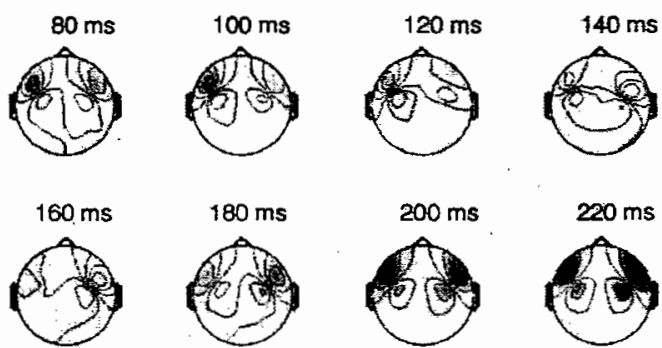

$180 \mathrm{~ms}$

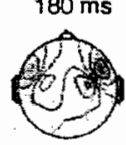

$200 \mathrm{~ms}$

$220 \mathrm{~ms}$
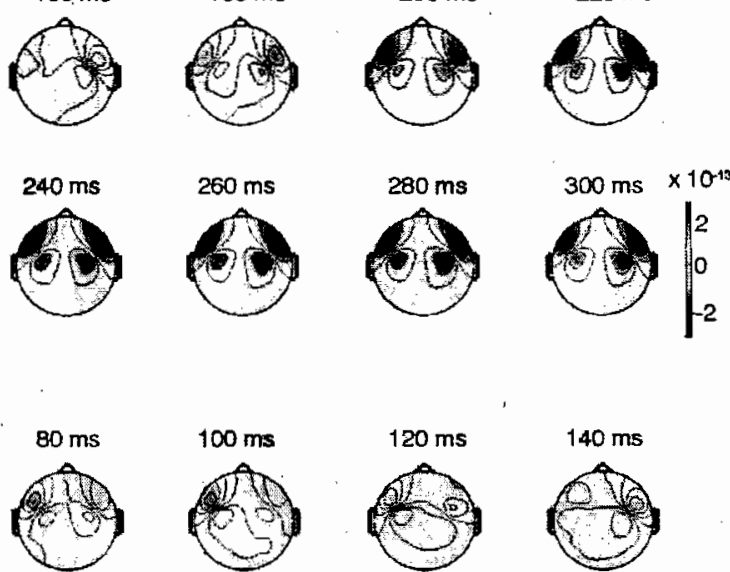

$200 \mathrm{~ms}$
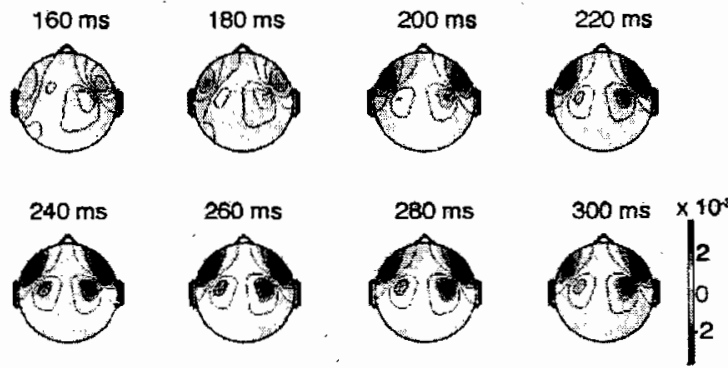

Fig. 2. Grand mean and topography maps of the standard condition (top: control children, bottom: dyslexic children). The butterfly plots show all MEG channels.

A reversal of field topography around $140 \mathrm{~ms}$, i.e. two separate sources with different orientations. The early source is oriented upwards pointing towards the vertex (seen as positive deflections in the event-related potential, ERP), and the later source is oriented downwards pointing towards the neck (seen as negative deflection in the ERP).

The signal-to-noise ratio did not differ statistically between the two groups $(F(1,74)=2.9, p=0.1)$. The mean number of averaged epochs was 384 for the dyslexic group and 391 in the control group.

\subsection{Early positive component}

ECD fits for the early component were not consistently stable and in many cases did not meet criteria (see Section 2) for statistical analysis. High quality ECDs in the right hemisphere could only be obtained for four control children. Thus, we decided not to assess the source locations of the early component.

\subsection{Late negative component}

ECD fits of 21 control children met criteria for statistical analysis for both the left and the right hemisphere. For the dyslexic children, 54 data sets of left hemispheric ECDs and 55 data sets of right hemispheric ECDs could be used ${ }^{2}$. Tables 3 and 4 summarise the dipole parameters.

Note that only dipoles with goodness of fit (GoF) values $>0.9$ were used. The average GoF-value for the control group was 0.976 , and 0.973 for the dyslexic group. Neither the GROUP main effect $(F(1,70)=0.62, p=0.43)$, nor the interaction GROUP $\times$ HEMISPHERE $(F(1,70)=0.10, p=0.75)$ were significant, indicating that the effects reported in the following are not a consequence of a diverging quality of dipole fits.

2 The groups did not differ in age $(F(1,74)=0.03, p=0.87)$, handedness $\left(X^{2}(1,74)=1.02, p=0.31\right)$ or gender distribution $\left(X^{2}(1,74)=0.27, p=0.6\right)$. 
Latencies and field amplitudes (RMS) for the two groups (LS-means \pm standard errors)

\begin{tabular}{lllll}
\hline & Left hemisphere & & \multicolumn{2}{c}{ Right hemisphere } \\
\cline { 2 - 3 } & Peak latency (ms) & RMS (fT) & Peak latency (ms) \\
\hline Controls & $265 \pm 4.68$ & $166.83 \pm 15.24$ & $277 \pm 4.68$ & $190.74 \pm 15.24$ \\
Dyslexics & $275 \pm 2.91$ & $172.10 \pm 9.42$ & $282 \pm 2.89$ & $185.51 \pm 9.35$ \\
\hline
\end{tabular}

Table 4

Dipole moments $(Q)$ and ECD locations (X: posterior-anterior, $Y$ : medial-lateral, $Z$ : inferior-superior) for the two groups (LS-means \pm standard errors)

\begin{tabular}{|c|c|c|c|c|c|c|c|c|}
\hline \multirow{2}{*}{. } & \multicolumn{4}{|c|}{ Left hemisphere } & \multicolumn{4}{|c|}{ Right hemisphere } \\
\hline & $Q(\mathrm{nAm})$ & $X(\mathrm{~cm})$ & $Y(\mathrm{~cm})$ & $Z(\mathrm{~cm})$ & $Q(\mathrm{nAm})$ & $X(\mathrm{~cm})$ & $Y(\mathrm{~cm})$ & $Z(\mathrm{~cm})$ \\
\hline \multirow[t]{2}{*}{ Controls } & 31.18 & $1.16^{\circ}$ & 5.37 & 5.35 & 32.47 & 1.71 & 5.30 & 5.22 \\
\hline & \pm 2.92 & \pm 0.15 & \pm 0.14 & \pm 0.17 & \pm 2.92 & \pm 0.15 & \pm 0.14 & \pm 0.17 \\
\hline \multirow[t]{2}{*}{ Dyslexics } & 29.73 & 1.24 & 5.34 & 5.27 & 33.90 & 1.39 & 5.35 & 5.10 \\
\hline & \pm 1.82 & \pm 0.09 & \pm 0.09 & \pm 0.10 & \pm 1.80 & \pm 0.09 & \pm 0.09 & \pm 0.10 \\
\hline
\end{tabular}

\subsection{Posterior-anterior axis position}

The interaction GROUP $\times$ HEMISPHERE $(F(1,70)=$ 4.12, $p=0.046$; effect size: $d=0.49, r=0.24$ ) was found. ECDs in the right hemisphere were localised more anterior than in the left hemisphere for the control children $(p=0.002)$. This hemispheric asymmetry was not present for the dyslexic children (see Fig. 3). There was a trend for ECDs being located more anterior for the control group than for the dyslexic group in the right hemisphere $(p=0.07)$.

\subsection{Dipole strength}

No main effects or interactions were obtained for the dependent variable dipole strength.

\subsection{Latency}

The main effect HEMISPHERE $(F(1,70)=7.17$, $p<0.005$; effect size: $d=0.64, r=0.3$ ) was revealed. The RMS peak occurred later after stimulus presentation in the right hemisphere $(261 \mathrm{~ms})$ than in the left hemisphere (252 ms). Further, a trend towards the main effect GROUP

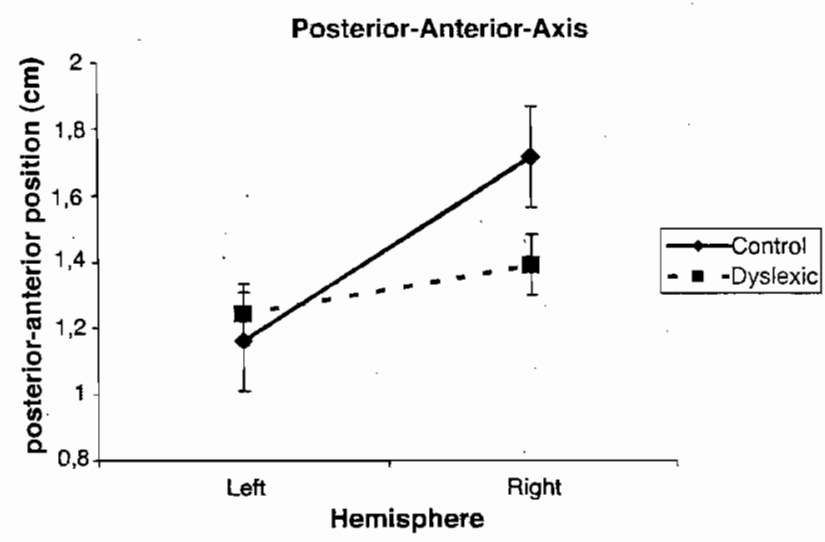

Fig. 3. Interaction GROUP $\times$ HEMISPHERE.
$(F(1,70)=3.30, p=0.07$; effect size: $d=0.43, r=0.21)$ was found. The RMS peak occurred earlier for the control group (252 ms) than for the dyslexic children $(260 \mathrm{~ms})$.

\subsection{Correlations}

A moderate but significant correlation was found between the asymmetry index and performance in the DRT ( $r=0.3$, $p<0.05)$. Fig. 4 displays that a greater hemispheric asymmetry was related to better spelling test performance. Calculating correlations for the two groups separately demonstrated that this effect was mainly to be driven by the control group. The correlation coefficient between the asymmetry index and performance in the DRT was $0.55(p<0.05)$ for the control group and -0.02 (n.s.) for the dyslexic group.

For further investigation we separated the dyslexic children into two groups based on their categorical perception performance. Children with categorical perception indices $<25$ (see Fig. 5) were classified as poor categorical perceivers. Comparing good and poor categorical perceivers statistically revealed no significant effects.

Linear relationship between asymmetry index and spelling test pertormance $X($ right $)-X($ left $)=-0,5334+0,0183^{\prime} X$

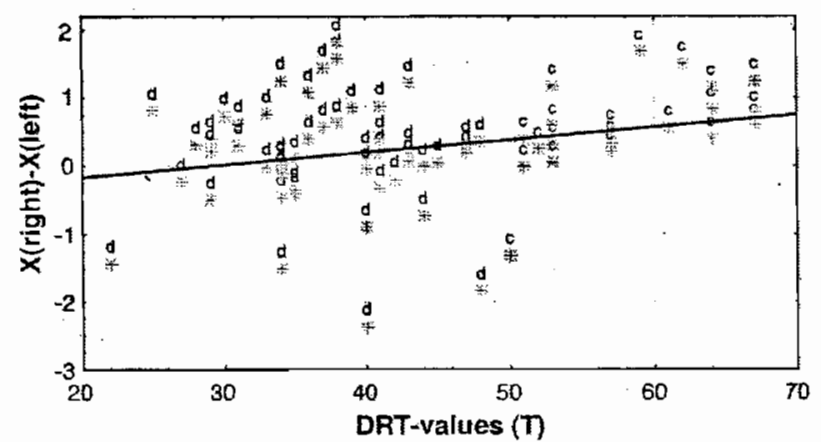

Fig. 4. Linear relationship between asymmetry index and performance in the standardised spelling test (DRT), c: control children, d: dyslexic children. 


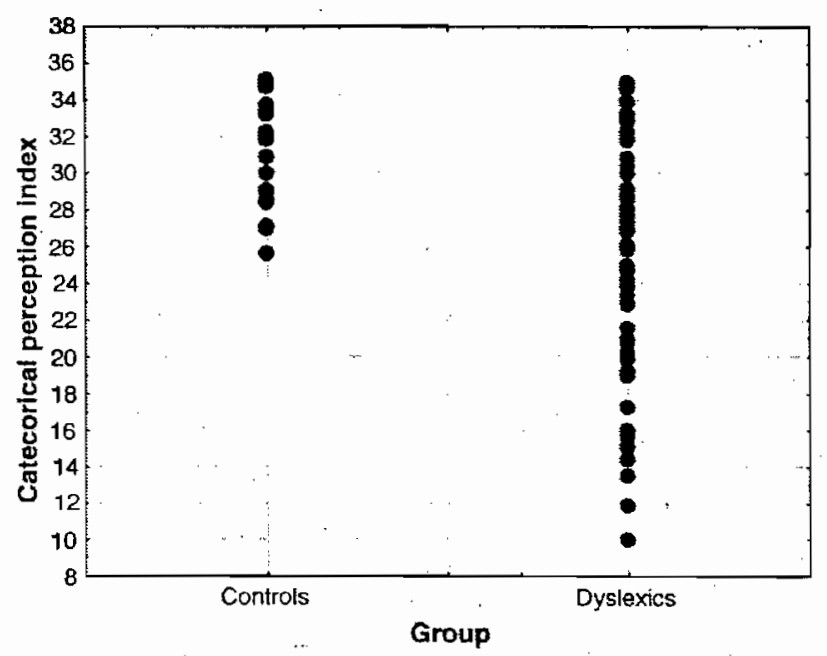

Fig. 5. Scatter plot of categorical perception performance. High index values indicate reliable and conect categorisation of $/ \mathrm{ba} /$ and $/ \mathrm{da} /$.

\section{Discussion}

In accord to several other studies (Eulitz et al., 1995; Heim et al., 2003a,b; Ohtomo et al., 1998; Paetau et al., 1995; Teale et al., 1998), we found right hemispheric ECDlocalisations of the syllable $/ \mathrm{ba} /$ to be more anterior than left hemispheric ECDs in our sample of normally literate children. This asymmetry was not present for the dyslexic children. Our finding replicates results of Heim et al. (2003a,b), who also found more symmetrical ECD localisations for their dyslexic samples - an effect, that was mainly driven by group differences in the right hemisphere. However, Heim et al. (2003a,b) observed ECD deviations of the N100m component in dyslexic adults and the $P 100 \mathrm{~m}$ component in dyslexic children. In the present study, source asymmetry differences were found for the later $\mathrm{N} 260 \mathrm{~m}$ component, which was found to be normally distributed in the Heim et al. study involving children. This difference might be explained by varying sample sizes ( $n=14$ for (Heim et al., 2003b); $n=55$ in the present study) and age distributions (8-16 years for (Heim et al., 2003b); $8-10$ years in the present study). A generally high heterogeneity in the phenotype of dyslexia (Demonet, Taylor, \& Chaix, 2004; Frith, 2001) might also contribute to differences in sample characteristics. The discrepant findings may well reflect the mixed results characterising the current MEG literature on clinical populations (Breier et al., 2003; Helenius, Salmelin, Richardson, Leinonen, \& Lyytinen, 2002; Parviainen Helenius, \& Salmelin, 2005). It is thus not surprising that a complex developmental disorder such as dyslexia is not associated with a single neural substrate.

The N260m source was the earliest source oriented downward (negative ERP deflection) in our data. It was preceded by a source oriented upwards (positive ERP deflection) at around $100 \mathrm{~ms}$. A P1/N2 complex with latencies very similar to those reported here has repeatedly been shown for auditory
ERP/ERF data in children (Albrecht et al., 2000; Ceponiene et al., 2002; Courchesne, 1990; Heim et al., 2003a,b; Korpilahti \& Lang, 1994; Sharma, Kraus, McGee, \& Nicol, 1997). An adult-like N1/P2 complex seems to reliably occur not until adolescence (Albrecht et al., 2000; Ceponiene et al., 2002; Paetau et al., 1995; Ponton et al., 2002; Takeshita et al., 2002). Different ERP/ERF morphologies of children are thought to reflect maturational aspects like enhanced refractory periods (Rojas et al., 1998) or development of cortical layers (Ponton et al., 2002).

It is unclear, whether and which of the adult components correspond to the ones of children (Sharma et al., 1997). Some authors argue that the child N250 is commensurate with the adult N100 (Korpilahti and Lang, 1994; Kurtzberg, Vaughan, Kreuzer, \& Fliegler, 1995), while other authors think of it as a counterpart of the adult N2. Paetau et al. (1995) noticed that an adult-like $\mathrm{N} 1 \mathrm{~m}$ response occurred in children when longer ISIs were used $(1.2-2.4 \mathrm{~s})$. Ceponiene, Cheour and Näätänen (1998) discovered two additional negative components (N160 and 460) besides the N250 in their sample of children when ISIs were longer than $2 \mathrm{~s}$. The authors interpreted the fronto-centrally distributed N160 as a correlate of the adult N1. In their 2002 study (Ceponiene et al., 2002) an adult-like N1 could be detected in the ERP data of 9-year-old after the slow N2 activity was filtered out.

Albrecht et al. (2000) found no differences between children and adults when localising N250, N1 and N2. Ceponiene et al. (2002) localised N1 and N2 sources of both adults and children in supratemporal areas with N2 sources being close by but more anterior. Takeshita et al. (2002) also localised the $\mathrm{N} 250 \mathrm{~m}$ anterior to the $\mathrm{N} 100 \mathrm{~m}$.

To sum up, it appears that longer ISIs are necessary to elicit adult-like auditory ERP/ERF components in children. With short ISIs, the negative component complex found around $250 \mathrm{~ms}$ in children might consist of overlapping N1 and N2 responses. It nevertheless seems that the N250m - despite lying anterior to the $\mathrm{N} 1$ - originates in supratemporal areas.

In contrast to control children we found rather symmetrical ECD localisations for dyslexic children. This might be an effect of a more symmetrical PT formation in dyslexia (Eckert et al., 2001; Galaburda et al., 1985; Humphreys et al., 1990; Hynd et al., 1990; Larsen et al., 1990; Schultz et al., 1994). PT asymmetry has been found to increase throughout childhood (Sowell et al., 2002). Therefore, symmetrical auditory ECD localisations in dyslexia might be interpreted as an indication of a maturational lag. This view is supported by our findings concerning $\mathrm{N} 260 \mathrm{~m}$ latency. In accord to left hemispheric specialisation for language, left hemispheric latencies were shorter than right hemispheric latencies for both groups. However, control children showed an earlier activation peak ( $252 \mathrm{~ms}$ ) post stimulus than dyslexic children $(260 \mathrm{~ms})$. Latencies of late auditory evoked potentials are longer in children than in adults (e.g. Ponton et al., 2002). Albrecht et al. (2000) showed that a latency decrease occurs until adolescence. Thus, prolonged latencies in dyslexia might reflect a maturational delay. Other authors 
also found increased ERP/ERF latencies for their dyslexic samples. This was explained by an abnormal auditory processing pattern in dyslexia (Neville, Coffey, Holcomb, \& Tallal, 1993), slower processing of auditory pathways due to delayed maturation (Tonnquist-Uhlén, 1996) and subtle difficulties in the perception of consonants (Helenius et al., 2002). The view of Helenius et al., (2002) is of relevance to our results as well, since the consonant took up the first $40 \mathrm{~ms}$ of the CV syllable /ba/ we presented.

While ECD localisations were very similar between dyslexic and control children in the left hemisphere, they differed in the right hemisphere. It is possible that right hemispheric areas involved in speech processing for the dyslexic subjects are less efficient than the ones active in control subjects. This interpretation is backed by the correlation between the asymmetry index and spelling test performance in the present study. It is noteworthy that the modest correlation between asymmetry index and spelling test performance over all children was mainly driven by the control group. This implies that in the group of unaffected children, greater asymmetry is related to better spelling test performance, whereas this does not seem to be the case in dyslexic children.

Our findings are in line with the results of Eckert et al. (2001), who found planum temporale asymmetry to be a predictor of phonological abilities in right-handed children. However, our findings contrast results of Leonard et al. (2002), who found that children with phonological dyslexia (children with poor phonological abilities) are more likely to have asymmetrical planar structures (planum temporale and parietale) than children with average phonological abilities. They also, found that normal children with pronounced asymmetrical planar structures had poorer phonological decoding abilities. It should be noted however, that normal children with more symmetrical structures were also found to have poorer phonological decoding abilities, reading comprehension and verbal abilities than children with moderate asymmetries. In the present study, children with good and poor phonological abilities within the dyslexic group did not differ statistically in terms of their asymmetry indices. Taken together it appears that findings are inconsistent in terms of phonological abilities and symmetry of brain structures.

The lack of asymmetry in the dyslexic group arose from more posterior ECD locations in the right hemisphere. If the involvement of aberrant right temporal regions as found in this study is the origin or the consequence of dyslexic symptoms remains unclear, however. Right hemispheric deviances have also been reported by McCrory et al. (2000), who found a right hemispheric underactivation in their dyslexic sample during repetition of words and pseudowords. In contrast, Corina et al. (2001) reported an increased right hemispheric activation in the right PT during a phonological judgement task in dy slexic subjects. These controversial results might be explained by the use of different methods (PET and fMRI), as well as different tasks and samples (children and adults).
Nevertheless, it seems that not only the language-specific left hemisphere is deviant in dyslexics (e.g. Paulesu et al., 1996; Rumsey et al., 1997; Temple et al., 2001) but also the right hemisphere.

In conclusion, our results support the notion of a deviating cortical organisation in dyslexia. Reduced hemispheric asymmetry in the localisation of auditory ERF components in dyslexia appears to be a robust finding across different samples of dyslexic children and adults. It appears that different cortical areas are involved in auditory (language) processing in dyslexic subjects compared to control sunjects. This might be the consequence of a more symmetrical PT formation. However, this issue can only be clarified by coregistration of functional MEG and structural magnetic resonance images in children.

\section{References}

Albrecht, R., Suchodoletz, W., \& Uwer, R. (2000). The development of auditory evoked dipole source activity from childhood to adulthood. Clinical Neurophysiology, $111(12), 2268-2276$.

Bishop, D. V., \& Snowling, M. J. (2004). Developmental dyslexia and specific language impairment: Same or different? Psychological Bulletin, 130(6), 858-886.

Breier, J. I., Simos, P. G., Fletcher, J. M., Castillo, E. M., Zhang, W., \& Papanicolaou, A. C. (2003). Abnormal activation of temporoparietal language areas during phonetic analysis in children with dyslexia. Neuropsychology, 17(4), 610-621.

Brunswick, N., McCrory, E., Price, C. J., Frith, C. D., \& Frith, U. (1999). Explicit and implicit processing of words and pseudowords by adult developmental dyslexics: A search for Wemicke's Wortschatz? Brain, 122(Pt 10), 1901-1917.

Ceponiene, R., Cheour, M., \& Näätanen, R. (1998). Interstimulus interval and auditory event-related potentials in children: Evidence for multiple generators. Electroencephalography and Clinical Neurophysiology, 108(4), 345-354

Ceponiene, R., Rinne, T., \& Näätanen, R. (2002). Maturation of corti$\mathrm{cal}$ sound processing as indexed by event-related potentials. Clinical Neurophysiology, 113(6), 870-882.

Corina, D. P., Richards, T. L., Serafini, S., Richards, A. L., Steury, K., Abbott, R. D., et al. (2001). fMRI auditory language differences between dyslexic and able reading children. Neuroreport, 12(6), 1195-1201.

Courchesne, E. (1990). Chronology of postnatal human brain development: Event-related potential, positron emission tomography, myelinogenesis, and synaptogenesis studies. In R. JW, J R, \& J. Johnson (Eds.), Event-reiated potentials: basic issues and applications (pp. 210-241). Oxford: Oxford University Press.

Demonet, J. F., Taylor, M. J., \& Chaix, Y. (2004). Developmental dyslexia. Lancet, 363(9419), 1451-1460.

Eckert, M. A., Lombardino, L. J., \& Leonard, C. M. (2001). Planar asymmetry tips the phonological playground and environment raises the bar. Child Development, 72(4), 988-1002.

Engelien, A., Silbersweig, D., Stern, E., Huber, W., Doring, W., Frith, C., et al. (1995). The functional anatomy of recovery from auditory agnosia A PET study of sound categorization in a neurological patient and normal controls. Brain, $118(\mathrm{Pt} 6), 1395-1409$.

Eulitz, C., Diesch, E., Pantev, C., Hampson, S., \& Elbert, T. (1995). Magnetic and electric brain activity evoked by the processing of tone and vowel stimuli. Journal of Neuroscience, 15(4), 27482755 . 
Fiez, J. A., Raichle, M. E., Balota, D. A., Tallal, P., \& Petersen, S. E. (1996). PET activation of posterior temporal regions during auditory word presentation and verb generation. Cerebral Cortex, 6(1), 1-10.

Findeisen, U., \& Melenk, G. (1991). Lauttreue diktate für die 1. bis 5 klasse. Bochum: Winkler.

Frith, U. (2001). What framework should we use for understanding developmental disorders? Developmental Neuropsychology, 20(2), 555-563.

Galaburda, A. M., \& Geschwind, N. (1981). Anatomical asymmetries in the adult and developing brain and their implications for function. Advances in Pediatrics, 28, 271-292.

Galaburda, A. M., Sherman, G. F., Rosen, G. D., Aboitiz, F., \& Geschwind, N. (1985). Developmental dyslexia: Four consecutive patients with cortical anomalies. Annals of Neurology, 18(2), 222-233.

Gauger, L. M., Lombardino, L. J., \& Leonard, C. M. (1997). Brain morphology in children with specific language impairment. Journal of Speech Language and Hearing Research, 4O(6), 1272-1284.

Geschwind, N., \& Galaburda, A. M. (1987). Cerebral lateralization. London: MIT Press.

Grissemann, H. (2000). Zürcher lesetest (ZLT). Bem: Hans Huber.

Grund, M., Haug, G., \& Naumann, C. (1994). Diagnostischer rechtschreibtest für 4. Klassen (DRT4). Weinheim, Basel: Beltz.

Heim, S., Eulitz, C., \& Elbert, T. (2003a). Altered hemispheric asymmetry of auditory $\mathrm{N} 100 \mathrm{~m}$ in adults with developmental dyslexia. Neuroreport, 14(3), 501-504

Heim, S., Eulitz, C., \& Elbert, T. (2003b). Altered hemispheric asymmetry of auditory P100m in dyslexia. European Journal of Neuroscience, $17(8), 1715-1722$

Helenius, P., Salmelin, R., Richardson, U., Leinonen, S., \& Lyytinen, H. (2002). Abnormal auditory cortical activation in dyslexia $100 \mathrm{~ms}$ after speech onset. Journal of Cognitive Neuroscience, 14(4), 603-617.

Heller, K., Kratzmeier, H., \& Lengfelder, A. (1998). Raven-Matrizen-test standard progressive matrices (SPM). Deutsche version. Göttingen: Beltz.

Humphreys, P., Kaufmann, W. E., \& Galaburda, A. M. (1990). Developmental dyslexia in women: Neuropathological findings in three patients. Annals of Neurology, 28(6), 727-738.

Hynd, G. W., Semrud-Clikeman, M., Lorys, A. R., Novey, E. S., \& Eliopulos, D. (1990). Brain morphology in developmental dyslexia and attention deficit disorder/hyperactivity. Archives of Neurology, 47(8), 919-926.

Jäncke, L., Wüstenberg, T., Scheich, H., \& Heinze, H. J. (2002). Phonetic perception and the temporal cortex. Neuroimage, 15(4), 733-746.

Jemigan, T. L., Hesselink, J. R., Sowell, E., \& Tallal, P. A. (1991) Cerebral structure on magnetic resonance imaging in language- and learning-impaired children. Archives of Neurology, 48(5), 539-545.

Korpilahti, P., \& Lang, H. A. (1994). Auditory ERP components and mismatch negativity in dysphasic children. Electroencephalography and Clinical Neurophysiology, 91(4), 256-264.

Kurtzberg, D., Vaughan, H. G., Jr., Kreuzer, J: A., \& Fliegler, K. Z. (1995). Developmental studies and clinical application of mismatch negativity: Problems and prospects. Ear and Hearing, 16(1), 105-117.

Larsen, J. P., Hoien, T., Lundberg, I., \& Odegaard, H. (1990). MRI evaluation of the size and symmetry of the planum temporale in adolescents with developmental dyslexia. Brain and Language, 39(2), 289-301.

Leonard, C. M., Lombardino, L. J., Walsh, K., Eckert, M. A., Mockler, J. L., Rowe, L. A., et al. (2002). Anatomical risk factors that distinguish dyslexia from SLI predict reading skill in normal children. Journal of Communication Disorders, 35, 501-531.

McCrory, E., Frith, U., Brunswick, N., \& Price, C. (2000). Abnormal functional activation during a simple word repetition task: A PET study of adult dyslexics. Journal of Cognitive Neuroscience, 12(5), 753-762.

Müller, R. (1997). Diagnostischer rechtschreibtest für 3. Klassen (DRT3). Weinheim, Basel: Beltz

Neville, H., Coffey, S., Holcomb, P., \& Tallal, P. (1993). The neurobiology of sensory and language processing in language-impaired children Journal of Cognitive Neuroscience, 5(2), 235-253.
Ohtomo, S., Nakasato, N., Kanno, A., Hatanaka, K., Shirane, R., Mizoi, K., \& Yoshimoto, T. (1998). Hernispheric asymmetry of the auditory evoked $\mathrm{N} 100 \mathrm{~m}$ response in relation to the crossing point between the central sulcus and Sylvian fissure. Electroencephalography Clinical Neurophysiology, 108(3), 219-225.

Paetau, R., Ahonen, A., Salonen, O., \& Sams, M. (1995). Auditory evoked magnetic fields to tones and pseudowords in healthy children and adults. Joumal of Clinical Neurophysiology, 12(2), 177185.

Parviainen, T., Helenius, P., \& Salmelin, R. (2005). Cortical differentiation of speech and nonspeech sounds at $100 \mathrm{~ms}$ : Implications for dyslexia. Cerebral Cortex, 15(7), 1054-1063.

Paulesu, E., Frith, U., Snowling, M., Gallagher, A., Morton, J., Frackowiak, R. S, et al. (1996). Is developmental dyslexia a disconnection syndrome? Evidence from PET scanning. Brain, 119(Pt 1), 143157.

Ponton, C., Eggermont, J. J., Khosla, D., Kwong, B., \& Don, M. (2002). Maturation of human central auditory system activity: Separating auditory evoked potentials by dipole source modeling. Clinical Neurophysiology, 113(3), 407-420.

Rojas, D. C., Walker, J. R., Sheeder, J. L., Teale, P. D., \& Reite, M. L. (1998). Developmental changes in refractoriness of the neuromagnetic M100 in children. Neuroreport, 9(7), 15431547.

Rumsey, J. M., Donohue, B. C., Brady, D. R., Nace, K., Giedd, J. N., \& Andreason, P. (1997). A magnetic resonance imaging study of planum temporale asymmetry in men with developmental dyslexia. Archives of Neurology, 54(12), 1481-1489.

Schultz, R. T., Cho, N. K., Staib, L. H., Kier, L. E., Fletcher, J. M., Shaywitz, S. E., et al. (1994). Brain morphology in normal and dyslexic children: The influence of sex and age. Annals of Neurology, 35(6), 732-742.

Shapleske, J., Rossell, S. L., Woodruff, P. W., \& David, A. S. (1999). The planum temporale: A systematic, quantitative review of its structural, functional and clinical significance. Brain Research Reviews, 29(1), 26-49.

Sharma, A., Kraus, N., McGee, T. J., \& Nicol, T. G. (1997). Developmental changes in P1 and N1 central auditory responses elicited by consonant-vowel syllables. Electroencephalography and Clinical Neurophysiology, 104(6), 540-545.

Shaywitz, S. E., Shaywitz, B. A., Pugh, K. R., Fulbright, R. K., Constable, R. T., Mencl, W. E., et al. (1998). Functional disruption in the organization of the brain for reading in dyslexia. National Academy of Sciences of the United States of America, 95(5), 26362641.

Sowell, E. R., Thompson, P. M., Rex, D., Kornsand, D., Tessner, K. D., Jernigan, T. L., et al. (2002). Mapping sulcal pattern asymmetry and local cortical surface gray matter distribution in vivo: Maturation in perisylvian cortices. Cerebral Cortex, 12(1), 1726.

Steinmetz, H. (1996). Structure, functional and cerebral asymmetry: In vivo morphometry of the planum temporale. Neuroscience and Biobehavioral Reviews, 20(4), 587-591.

Takeshita, K., Nagamine, T., Thuy, D. H., Satow, T., Matsuhashi, M., Yamamoto, J., et al. (2002). Maturational change of parallel auditory processing in school-aged children revealed by simultaneous recording of magnetic and electric cortical responses. Clinical Neurophysiology, $113(9), 1470-1484$.

Teale, P., Sheeder, J., Rojas, D. C., Walker, J., \& Reite, M. (1998) Sequential source of the M100 exhibits inter-hemispheric asymmetry. Neuroreport, 9(11), 2647-2652.

Temple, E., Poldrack, R. A., Salidis, J., Deutsch, G. K., Tallal, P., Merzenich, M. M., et al. (2001). Disrupted neural responses to phonological and orthographic processing in dyslexic children: An fMRI study. Neuroreport, 12(2), 299-307.

Thompson, P. M., Giedd, J. N., Woods, R.'P., MacDonald, D., Evans, A. C., \& Toga, A. W. (2000). Growth patterns in the developing 
brain detected by using continuum mechanical tensor maps. Nature, 404(6774), 190-193.

Toga, A. W., \& Thompson, P. M. (2003). Mapping brain asymmetry. Nature Reviews Neuroscience, 4(1), 37-48.

Tonnquist-Uhlén, I. (1996). Topography of auditory evoked cortical potentials in children with severe language impaiment. Scandinavian Audiology, 44, 1-40 (Supplementum).
Tzourio, N., Massioui, F. E., Crivello, F., Joliot, M., Renault, B., \& Mazoyer, B. (1997). Functional anatomy of human auditory attention studied with PET. Neuroimage, 5(1), 63-77.

Welte, V. (1981). Der Mottiertest, ein Prüfungsmittel für die Lautdifferenzierungsfähigkeit und die auditive Merkfähigkeit. Sprache-StimmeGehör, 5, 121-125. 